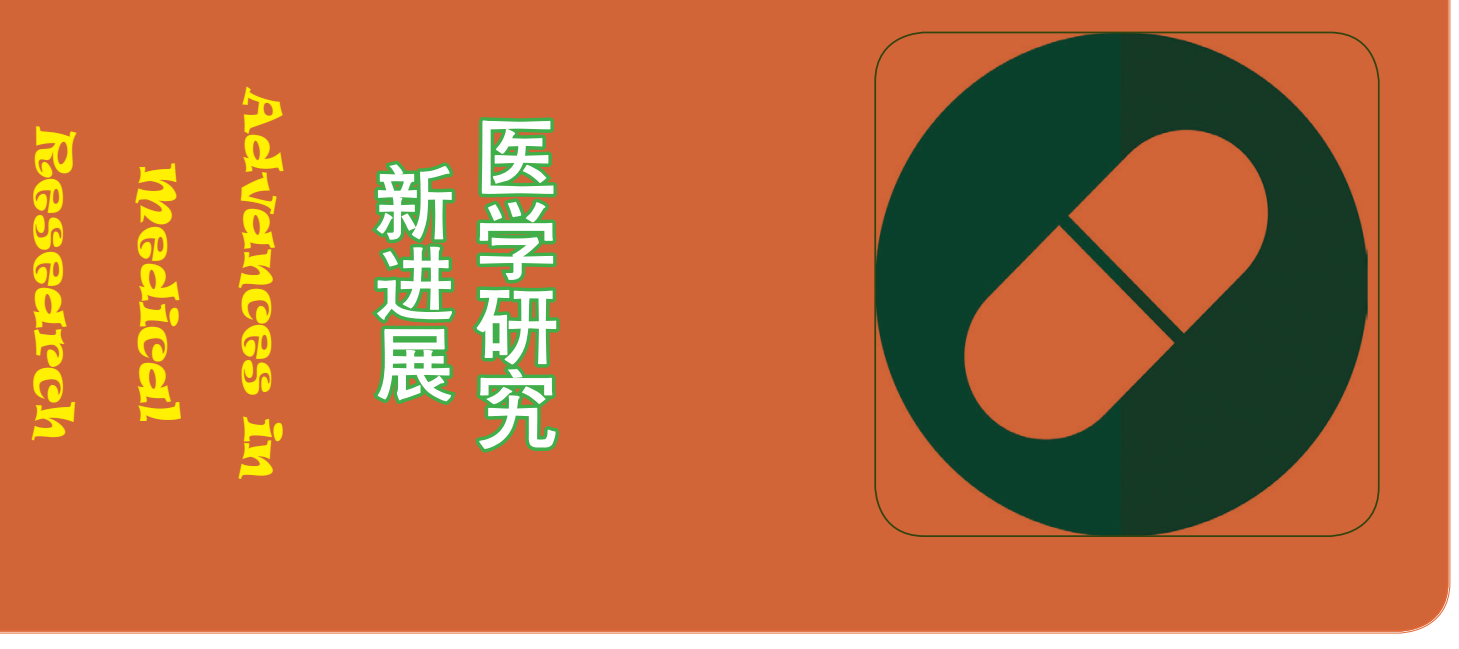

\section{人每天是否需要喝 八杯水?}

$$
\text { Mike Wang }
$$

University of Illinois at Urbana-Champaign

《美国国家科学院院刊》在线报道了莫纳什大学 主导的多中心研究, 首次揭示了调节人体内水摄入的 “吞咽抑制” 机制, 这一机制可防止饮水过度所导致 的水中毒。本研究发现冲击了 “每天喝八杯水” 的传 统观点。

人饮水以补充体液消耗以及满足渴欲。当血液中 钠离子处于异常低的水平时会导致昏睡、恶心、惊厥、 甚至昏迷，所以人喝水过多会导致水中毒或者低钠 血症。目前对人渴了到底应该喝多少量的水才够还 不清楚，不过已有研究证据揭示：“吞咽抑制” 是控 制人应该喝多少水的其中一个可能的调节因子。通 过使用功能性核磁共振成像技术, 研究人员调查人 饮水过量后是否会引起吞咽抑制反应。
研究人员让参与者在两种情况下来评估吞咽时 所需的力量: 一是运动后渴了时的情况; 另外一种 就是过量饮水。结果表明: 过量饮水时比渴了时喝 水所需的吞咽力量高了三倍, 而在过量饮水前后在 水中添加 $8 \%(\mathrm{wt} / \mathrm{vol})$ 的蔗糖对对吞咽动作没有大 的影响。研究人员同时使用功能性核磁共振成像技 术来测量参与者大脑不同部位的活动, 主要检查 吞咽水前瞬间的大脑的活动。相对于渴了饮水, 过 量饮水后参与者脑部的运动皮质、前额皮质、后 顶叶皮质，纹状体和丘脑部位反映增强; 而吞咽时 力量与脑干右侧前额叶皮层和脑桥区域的反应性有 关联。

这一发现进一步支持了过量饮水后吞咽抑制调 节机制的存在，这一机制在调节人体水的摄入量方 面有重大意义。

\section{参考文献}

[1] Saker P, Farrell MJ, Egan GF, McKinley MJ, Denton DA. Overdrinking, swallowing inhibition, and regional brain responses prior to swallowing. Proc Natl Acad Sci U S A 2016;113(43):12274-12279. doi:10.1073/ pnas. 1613929113 